\title{
Os trabalhadores da educação e a construção política da profissão docente no Brasil $^{1}$
}

\section{Workers in education and political construction of the teaching profession in Brazil}

\author{
Dalila Andrade Oliveira ${ }^{2}$
}

\begin{abstract}
RESUMO
Este artigo analisa a constituição da profissão docente no Brasil, partindo do reconhecimento de que a profissionalização cresce na educação na proporção em que são ampliados os sistemas escolares. Analisando que os estudos sobre a profissão docente advêm de vertentes distintas (pedagógica, humanista e sociológica) e dos desdobramentos dessas concepções e estudos, a autora mostra a dimensão do problema da ambiguidade entre o profissionalismo e a proletarização na constituição da identidade profissional docente. $\mathrm{O}$ trabalho destaca que a profissão docente tem sido posta a pressões e câmbios advindos das novas regulações nos marcos das reformas educacionais dos anos 1990, de sorte que os padrões de organização educacional e escolar decorrentes dessas mudanças podem estar constituindo um novo perfil de trabalhador docente e uma nova identidade. O texto conclui analisando os impactos daquelas mudanças na profissionalização do magistério, que podem ser responsáveis pela alteração de duas faces
\end{abstract}

1 Este artigo foi desenvolvido a partir de conferência proferida no Seminário Internacional sobre Política Educativa y Territorios do IIPE/UNESCO (Instituto Internacional de Planejamento Educacional United Nations Educational, Scientific and Cultural Organization), realizado em Buenos Aires, nos dias 2 e 3 de outubro de 2008.

2 Professora do Programa de Pós-Graduação e da Faculdade de Educação da Universidade Federal de Minas Gerais. Coordenadora da Rede Latino-americana de Estudos Sobre Trabalho Docente e do Grupo de Trabalho (RedEstrado). Presidente da Associação Nacional de Pós-Graduação Pesquisa em Educação - ANPEd. Pesquisadora do Conselho Nacional de Desenvolvimento Científico e Tecnológico - CNPq - Brasil. E-mail: dalilaufmg@yahoo.com.br. 
importantes do trabalho docente: no que concerne ao objeto do trabalho e no que tange à organização do trabalho.

Palavras-chave: Trabalho docente; profissão docente; reformas educacionais.

\begin{abstract}
This paper examines the teaching profession in Brazil, based on the recognition that the growing professionalism in education is connected to the extension of school systems. Analyzing that the studies on the teaching profession come from different aspects (pedagogical, humanistic and sociologic) and from the development of these concepts and studies, the author shows the extent of the ambiguity problem between professionalism and proletarian mode in the constitution of professional identity. The paper highlights that the profession has been submitted to pressure and exchanges that are consequences of new regulations within the framework of the educational reforms of the 1990s, so that patterns of educational organization and school organization may be due to those changes as well as constituting a new profile of teachers, and a new identity. This work concludes by analyzing the impacts of those transformations in the professionalization of teaching, which can be the reason for a variation of two important faces of teaching: in relation to the object of work and with regard to work organization.
\end{abstract}

Keywords: Teacher work; teaching profession, educational reforms.

Este artigo pretende discutir o movimento de construção da profissão docente presente nos movimentos de organização dos trabalhadores de Educação no Brasil nas últimas décadas. Parte da ideia de que a noção de profissionalização esteve presente na organização dos trabalhadores de educação a partir da organização e expansão dos sistemas escolares. Muitos autores se ocuparam desta discussão em diferentes contextos nacionais ${ }^{3}$, apresentando algumas semelhanças nas análises que apresentaram sobre diferentes contextos. De modo geral, observa-se relativa aceitação de que o magistério constitui-se como um corpo de trabalhadores que historicamente tem se orientado rumo à profissionalização. Em suas origens, os sujeitos que se ocupavam do ato de ensinar o faziam por vocação ou sacerdócio. Com o desenvolvimento da sociedade moderna, o ma-

3 Apple (1995); Hargreaves (1998), Nóvoa (1991, 1993), Lessard e Tardif (2004), Contreras (2002), Tenti Fanfani $(2005,2007)$, entre outros. 
gistério passou a constituir-se como um ofício em busca da profissionalização. Esta é uma tese que encontra bastante acolhida na literatura pertinente ao tema.

Tomando o conceito genérico de profissão como um termo que se refere a atividades especializadas, que possuem um corpo de saberes específico e acessível apenas a certo grupo profissional, com códigos e normas próprias e que se inserem em determinado lugar na divisão social do trabalho, pode-se indagar até que ponto o magistério obteve ou obtém condições de se definir como tal. Talvez a profissionalização, compreendida como o ato de buscar transformar em profissional algo que se faz de maneira amadora, no caso do magistério, pudesse melhor designar o movimento de organização e busca de um lugar, no sentido do reconhecimento social e do valor econômico de um determinado grupo profissional que comporta no seu interior distinções e complexidades que não lhe permitem identificar-se como profissão no seu sentido mais estrito. Assim, a profissionalização do magistério pode ser compreendida como um processo de construção histórica que varia com o contexto socioeconômico a que está submetida, mas que, sobretudo, tem definido tipos de formação e especialização, de carreira e remuneração para um determinado grupo social que vem crescendo e consolidando-se.

Compreende-se que o desenvolvimento da noção de profissionalização é resultado de uma forma específica de organização do Estado, a forma racional-burocrática de estruturação dos serviços públicos, que traz consigo a instituição de um corpo funcional. Os estudos de Max Weber sobre a burocracia nos trazem importantes elementos para compreender como se estrutura e se mantém em funcionamento uma organização de caráter racional, em que a impessoalidade e a autoridade conferida ao cargo tiveram assunção no Estado moderno, conferindo eficiência e legitimidade ao mesmo e, por estas razões, manteve-se predominante por tanto tempo. Os sistemas escolares modernos emergem da organização deste aparato estatal e se organizam como parte dependente dele. Assim, a primeira grande luta pela profissionalização do magistério esbarra no estatuto funcional que, por meio da conversão dos professores em servidores públicos e, portanto, funcionários do Estado, retira-lhe a autonomia e autocontrole sobre seu ofício. Como afirma Tenti Fanfani (2007), referindo-se a esse processo, nesse esquema organizacional os docentes ocuparam um status ambíguo:

Por una parte su actividad era definida como una misión cuya dignidad derivaba de la elevada función social que se le asignaba a la escuela (la conformación del ciudadano de la república moderna, el transmisión de valores universales que estaban más allá de toda discusión, la construcción de la idea de Patria, etc.). Pero por la otra el maestro era también un 
funcionario con un lugar muy preciso en una estructura jerárquica dominada por un conjunto de regulaciones y normas que definían con precisión sus responsabilidades, tareas e incumbencias. En pocas palabras, el docente era un apóstol y al mismo tiempo un funcionario, es decir, alguien a quien se le ha asignado una función claramente establecida en los marcos legales, formativos y regulativos que estructuran su actividad. A su vez, el trabajo del maestro era supervisado por una serie de "superiores jerárquicos" (el vice director, el director de escuela, el supervisor, etc.). Su actividad no sólo era regulada, sino también supervisada de cerca y en forma continua por una serie de agentes especializados.

Assim, talvez pudéssemos compreender a história dos trabalhadores da educação como um movimento resultante desta ambiguidade, de luta pela obtenção de um status profissional, mas usufruindo-se da condição de servidores públicos. $\mathrm{Ou}$, ainda, como a história de pretensos profissionais que foram se tornando funcionários públicos e que passaram a organizar-se na defesa de seus interesses, lutando contra alguns obstáculos que se interpuseram à condição de maior liberdade e autonomia no exercício do seu trabalho.

Segundo Rodrigues (2002), o conceito de profissão pode ser aceito como uma ocupação que exerce autoridade e jurisdição exclusiva, simultaneamente, sobre uma área de atividade e de formação ou conhecimento, tendo convencido o público de que os seus serviços são os únicos aceitáveis. Pode-se considerar, então, que a história de organização e constituição do magistério esteve marcada pela luta por constituir-se como profissão, mas que esta luta encontrou muitos obstáculos ao seu intento, sobretudo pelos corolários correspondentes a essa condição: autonomia, controle sobre o recrutamento, monopólio, estatuto único, entre outros. A insistência na construção dessa noção de profissionalização resultou em grandes debates acerca do tema nos estudos sobre a constituição do magistério.

Pode-se considerar que os estudos sobre a profissão docente são oriundos basicamente de duas vertentes. Uma primeira poderia ser descrita como aquela que se situa na tradição pedagógica humanista, que centra seu foco na formação docente, compreendida como um processo de constituição do sujeito no seu fazer pedagógico, atribuindo grande ênfase aos saberes adquiridos na experiência, à prática pedagógica e aos processos formativos. Essa vertente levada ao extremo acaba por atribuir demasiado peso à formação como elemento central da profissionalização. Nóvoa (2000), analisando as tendências atuais nos estudos sobre profissão docente, identifica a existência de uma literatura que reduz a profissão docente a um conjunto de competências e capacidades, realçando essencialmente a dimensão técnica da ação pedagógica. 
A segunda vertente pode ser identificada nas análises sobre a profissão docente trazidas pela perspectiva sociológica, em que a identidade profissional é compreendida na relação com suas atividades laborais, com a inserção desses sujeitos na divisão social do trabalho. As profissões constituem-se em importante objeto da sociologia desde seu nascedouro. Nas lições de Sociologia de Émile Durkheim as corporações profissionais são consideradas importantes mediações entre o Estado e os indivíduos. A organização dos grupos profissionais seria vital à coesão social e ao equilíbrio e harmonia nas relações entre sociedade política e Estado, já que por meio da divisão do trabalho é que se realiza a integração social.

$\mathrm{Na}$ vertente sociológica destacam-se duas distintas abordagens: estudos que se situam nos referenciais trazidos pela sociologia do trabalho, sobretudo, nas relações de trabalho, com preponderância na matriz marxista; e outra que se orienta pelas referências oferecidas pela sociologia das profissões. As teses sobre a proletarização, a desvalorização e a desqualificação do trabalho docente foram elaboradas a partir das referências da primeira orientação e/ou da confluência entre ambas. A ameaça à proletarização, caracterizada pela perda do controle do trabalhador da educação, em particular do professor, sobre o seu processo de trabalho, contrapunha-se à profissionalização como condição de preservação e garantia de um estatuto profissional que levasse em conta a autoregulação, a competência específica, rendimentos, licença para atuação, vantagens e benefícios próprios, independência etc. A discussão acerca da autonomia e do controle sobre o trabalho, nesta abordagem, é o ponto essencial.

As análises críticas que se produziram nesse contexto, no âmbito da educação, tendem a interpretar as relações de trabalho na escola como uma reprodução das relações de trabalho fabril. Apontavam nessa direção e traziam como principal elemento a ameaça ou perda efetiva de autonomia vivida pelos professores ante as reformas educacionais mais recentes. Tais reformas, resultantes da busca de adequação dos sistemas escolares à expansão da cobertura escolar, traziam novas normas de organização do ensino que tendiam à padronização de importantes processos, tais como o livro didático, as propostas curriculares centralizadas, as avaliações externas, entre outras. A padronização de tais procedimentos foi duramente criticada nessa abordagem por revelar uma tendência crescente à massificação da educação, com prejuízos nas condições de trabalho para os professores, trazendo consigo processos de desqualificação e desvalorização do corpo docente ${ }^{4}$.

No caso brasileiro, contraditoriamente, esta discussão surge em um momento (final dos anos 1970 e começo dos 1980) em que a história do movimento docente foi profundamente marcada pela luta pela profissionalização do 
magistério e reconhecimento de seus direitos. Talvez por esta razão, no contexto brasileiro, a ambiguidade, referida por Tenti Fanfani (2007), fosse mais flagrante, pois ao mesmo tempo em que, por um lado, se contestava a proletarização do magistério, por outro, a explorava na dimensão da luta de classes, da possibilidade de organização sindical desses trabalhadores como categoria profissional que se organiza por ramo de atividade econômica. A positividade ideológica posta pela proletarização, no sentido de promover o reconhecimento e autorreconhecimento do magistério como classe trabalhadora e de unir esforços a outras classes em uma dimensão político-transformadora, foi explorada pelas lideranças políticas e sindicais e por autores críticos 5 .

Mas, sem dúvida, a maior ambiguidade situava-se entre o profissionalismo e a proletarização, como advertia Enguita (1991). O autor chamou a atenção para o fato de que a profissionalização não seria sinônimo de capacitação, qualificação, conhecimento, formação, mas a "expressão de uma posição social e ocupacional, da inserção em um tipo determinado de relações sociais de produção e de processo de trabalho". Descreveu um grupo profissional como uma categoria autorregulada de pessoas que trabalham diretamente para o mercado numa situação de privilégio e monopólio, ressaltando que os profissionais são plenamente autônomos em seu processo de trabalho, não tendo de submeterem-se à regulação alheia. Já a proletarização é descrita pelo mesmo autor no sentido oposto ao que correntemente era dado à profissionalização.

A tese da proletarização aparece então como um processo irreversível em que os professores estão submetidos à medida que os sistemas escolares expandem sua cobertura e tal processo é compreendido como uma mazela da democratização do ensino. A discussão que se colocava à época está relacionada, então, à busca de autoproteção pelos professores e demais trabalhadores da educação por meio da luta pela profissionalização, pois a proletarização vinha acompanhada de um processo de desqualificação. Apple (1995) identificava a desqualificação sofrida pelos professores como uma tendência crescente ante a imposição de procedimentos de controle técnico sobre o currículo das escolas.

O paradigma central dessas análises repousa sobre a organização do trabalho fabril. Nesse sentido, o livro de Braverman, Trabalho e capital monopolista, que descreve o processo de expropriação histórica do saber operário ao longo das primeiras décadas do século XX, com a introdução da chamada Administração Científica do Trabalho, é uma referência essencial. A perda de autonomia e controle sobre o processo de trabalho está no centro dessas análises, tendo como referência o trabalho artesanal. Sustentam a tese de que cada trabalhador é historicamente expropriado de seu saber, controle, ritmo e produto 
de seu trabalho, gerando um processo de alienação e degradação do trabalho, resultante do capitalismo monopolista.

Assim, a profissionalização aparece nesse contexto como uma saída defensiva dos trabalhadores da educação aos processos de perda de autonomia no trabalho e de desqualificação, no sentido apontado por Braverman (1985), ou seja, o trabalhador que perde o controle sobre o processo de trabalho, perde a noção de integridade do processo, passando a executar apenas uma parte das tarefas e alienando-se de sua concepção. Por outro lado, a profissionalização parece indicar o contrário: ganho de status social, maior proteção, reserva de mercado, entre outros benefícios.

Nos dizeres de Nóvoa (1993, p. 23),

A profissionalização é um processo através do qual os trabalhadores melhoram o seu estatuto, elevam os seus rendimentos e aumentam o seu poder/autonomia. Ao invés, a proletarização provoca uma degradação do estatuto, dos rendimentos e do poder/autonomia; é útil sublinhar quatro elementos deste último processo: a separação entre a concepção e a execução, a estandardização das tarefas, a redução dos custos necessários à aquisição da força de trabalho e a intensificação das exigências em relação à actividade laboral.

Deste modo, a profissionalização constitui-se em verdadeiro instrumento de defesa contra o caráter normativo do Estado, já que como nos mostra Rodrigues (2002, p. 73):

o aumento do assalariamento e a entrada dos profissionais em organizações teriam como principal conseqüência a proletarização técnica - perda do controlo sobre o processo e produto do seu trabalho - e/ou a proletarização ideológica - que significa a expropriação de valores a partir da perda de controlo sobre o produto do trabalho e da relação com a comunidade.

A confluência das teses da profissionalização e da proletarização coloca em evidência o problema da identidade do magistério. São trabalhadores que não se veem plenamente como tal, pela herança e tradição que tem o magistério na noção de vocação e sacerdócio. A identificação como trabalhadores os remetem à condição economicamente determinada de que estão inseridos em relações objetivas e são contratados para executarem suas atividades ao longo de uma 
jornada, de forma subordinada, recebem um salário e do seu trabalho é retirado mais-valor. Esta identificação é objeto de fortes resistências, possivelmente por retirar esses trabalhadores do seu lugar tradicional.

Por outro lado, a identidade como profissionais tampouco atende exatamente ao reconhecimento que se busca. Os professores são em geral funcionários públicos ou empregados de instituições privadas que cada vez mais trabalham submetidos a orientações e controles exteriores. Segundo Nóvoa (2008), a crise de identidade dos professores, objeto de inúmeros debates ao longo dos últimos pelo menos vinte anos, relaciona-se com uma evolução que foi impondo a separação entre o eu pessoal e o eu profissional desses sujeitos. Para esse autor, a transposição dessa atitude do plano científico para o plano institucional contribuiu para intensificar o controle sobre os professores, favorecendo o seu processo de desprofissionalização.

É nesse contexto que a tese da tendência à desprofissionalização surge com bastante força, a despeito da profissionalização em si não ter sido sanada. Rodrigues (2002), em revisão de literatura sobre a produção na sociologia das profissões, explica que essa tendência observada em algumas profissões na atualidade se deve a diversos fatores, tais como: a emergência de consumidores menos passivos e com maiores expectativas de participação; a escolarização generalizada e universal, implicando melhoria nos níveis educativos e informacionais dos indivíduos, e, ainda; o aumento da especialização. Tudo isso teria como consequência a perda, por parte dos profissionais, da confiança dos clientes, o que resultaria em perda da autonomia, do poder e da autoridade.

O professor, diante das variadas funções que a escola pública assume, tem de responder a exigências para as quais não se sente preparado. Muitas vezes os trabalhadores docentes são obrigados a desempenharem funções de agente público, assistente social, enfermeiro, psicólogo, entre outras. Tais exigências contribuem para um sentimento de desprofissionalização, de perda de identidade, da constatação de que ensinar às vezes não é o mais importante ${ }^{6}$. Tal situação contribui ainda para a desvalorização e suspeita por parte da população de que o mais importante na atividade educativa está por fazer ou não é realizado com a competência esperada. Os exames externos promovidos pelos sistemas nacionais de avaliação, a busca permanente de mensuração do desempenho educacional dos alunos e a participação da família na gestão da escola traz muitas vezes o sentimento para os docentes de "estarem sob suspeita". Por parte desses outros agentes, é como se fossem reforçados permanentemente a fiscalizar a escola e o trabalho dos professores, manter uma vigilância próxima e permanente junto ao corpo docente.

6 Noronha (2001); Assunção e Oliveira (2009). 


\section{Os professores e a profissionalização}

Nóvoa (2000, p. 16) afirma que "A identidade é um lugar de lutas e conflitos, é um espaço de construção de maneiras de ser e estar na profissão". Esta acepção está fundada na ideia de que na construção dessa identidade a ação política está presente. A identidade é uma construção antes de tudo política.

No caso específico dos professores, esse autor observa certa indisponibilidade dos mesmos à mudança. Lembra que cada professor "tem o seu modo próprio de organizar as aulas, de se movimentar na sala, de dirigir-se aos alunos, de utilizar os meios pedagógicos, um modo que constitui uma segunda pele profissional” (NÓVOA, 2000, p. 16). Para o autor, os professores são um grupo profissional particularmente sensível ao efeito da moda e, ao mesmo tempo, que resiste à moda, o que denomina rigidez e plasticidade. Segundo ele, a adesão aos modismos levou certos pedagogos a criarem ortodoxias como a defesa contra o abastardamento dos seus métodos ou técnicas: "Uma vez na praça pública, as técnicas e os métodos pedagógicos são rapidamente assimilados, perdendo-se de imediato o controle sobre a forma como são utilizados" (NÓVOA, 2000, p. 17)

Depois de serem tomados como insumos e de terem sido ignorados pela primeira onda de reformas que marcou os anos 1950 e 1960 na América Latina, no seio do nacional-desenvolvimentismo, orientados pela Teoria do Capital Humano, os professores ressurgem nas reformas iniciadas nos anos 1990 como agentes centrais nos programas de mudança ${ }^{7}$. Eles passam agora ao outro extremo: são considerados os principais responsáveis pelo desempenho dos alunos, da escola e do sistema, tendo sobre suas costas a responsabilidade pelo êxito ou fracasso dos programas.

A participação dos profissionais docentes e da comunidade na elaboração, decisão e execução de determinadas políticas públicas para a educação passa a ser uma exigência no âmbito da gestão escolar, refletida na necessidade de se criarem mecanismos mais coletivos e participativos na escola. A gestão democrática da educação, com maior autonomia administrativa, financeira e pedagógica; a participação da comunidade na escola são exigências dos tempos atuais. Esses mecanismos, ao mesmo tempo em que buscam democratizar a escola, representam grande ameaça a esses profissionais no que se refere às supostas garantias de exclusividade sobre determinados terrenos, como a conhecida dificuldade em se pautarem discussões sobre conteúdos pedagógicos e práticas de avaliação nos conselhos escolares em que estão envolvidos alunos e pais. 
Muitos professores se veem ameaçados quando nesses espaços se busca abrir a chamada "caixa-preta" da sala de aula e, em geral, reagem duramente a essas tentativas. Abrir os conteúdos e práticas do seu fazer cotidiano é tomado por muitos professores como um atentado à sua condição profissional. Por outro lado, no extremo oposto, observa-se também, sobretudo, nos meios de comunicação de massa, a veiculação de uma ideia de que o que se faz na escola não é assunto de especialista, não exige um conhecimento específico e, portanto, pode ser discutido por leigos e praticado por voluntários. Esses dois extremos estão presentes no movimento de profissionalização docente e, se podemos entender o primeiro como uma defesa corporativa, o segundo tem sido interpretado, especialmente pelos próprios docentes como um processo de desprofissionalização.

Segundo Rodrigues (2002, p. 71): "A tendência para a desprofissionalização assenta naquilo a que se pode chamar mecanismos de desqualificação dos profissionais, de perda ou transferência de conhecimentos e saberes, seja para os consumidores, o público em geral, os computadores ou os manuais." Nessa perspectiva, os trabalhadores da educação estariam sofrendo processos de desprofissionalização por diversos fatores que variam desde a padronização dos meios de trabalho e introdução de tecnologias educativas em larga escala nas escolas até a deslegitimação dos seus saberes específicos resultante dos efeitos produzidos pelas avaliações externas que dão publicidade aos resultados vinculando o baixo rendimento dos alunos com o desempenho profissional dos docentes. Mas tal processo comporta uma complexidade que deve considerar mudanças na relação entre educação e sociedade e mesmo no papel que a escola desempenha na atualidade.

A principal crítica atribuída às profissões, de acordo com Rodrigues (2002), relaciona-se ao fato de o poder acumulado e as prerrogativas especiais de que usufruem serem utilizados em proveito próprio e não da coletividade, $o$ que constituiria um obstáculo, impedindo a maioria da população de ter normal acesso aos serviços que prestam. Nesse sentido, a autora adverte que a sociologia das profissões, ao transformar esta doutrina em teoria, cumpriu uma função ideológica, ajudando a legitimar e perpetuar o status quo.

A autonomia e o controle sobre o recrutamento, a formação, os títulos e o monopólio seriam prerrogativas de poder extensivas às profissões estabelecidas. Observa-se que os professores reagem muitas vezes com grande indignação às mudanças que lhes são impostas por meio da atuação de especialistas que não são da área. Outro fator que dá origem a resistências por parte dos professores é a abertura das escolas aos voluntários. As variadas campanhas em prol da educação para todos que apelam com frequência ao voluntariado têm promovido a desprofissionalização do espaço escolar no sentido apontado no início deste 
texto. Ou seja, caminham na contra-mão do movimento que tem por objetivo tornar o trabalho escolar profissional, abrindo-o constantemente aos amadores, aos que não foram formados e recrutados para este fim.

Rodrigues (2002, p. 42) observa que na ideologia do profissionalismo está presente a possibilidade de o conhecimento ser manipulado e modificado "a fim de melhor servir às necessidades dos membros da profissão, como meio de defesa, exclusividade e auto-perpetuação em face de ameaças de inovação e racionalização de tarefas e ocupação e também como instrumento nas lutas entre grupos ocupacionais disputando a mesma área". Nesse sentido as observações de Nóvoa sobre o caráter refratário às mudanças observado junto aos docentes poderiam estar revelando esta tentativa de autoproteção. Algumas evidências nesse sentido podem ser encontradas em pesquisas realizadas com colegiados escolares.

Para Popkewitz (1997) o rótulo profissão é, normalmente, utilizado para identificar um grupo especializado, altamente formado, competente e digno de confiança pública. Todavia, frequentemente, a profissão faz dos seus serviços uma forma de obtenção de prestígio, de poder e de status econômico, ou seja, desenvolve uma autoridade cultural e social. $\mathrm{O}$ argumento contrário aos processos de desprofissionalização do espaço escolar, trazidos pelas campanhas que apelam ao voluntariado, embasa-se na necessidade de titulação acadêmica, como a licença para o exercício do profissional responsável. A profissionalização passa a ser cada vez mais uma outorga do Estado, por meio de diplomas mais do que pelo reconhecimento de um saber obtido na experiência, no desempenho de um ofício. A certificação para o exercício do magistério tem sido um tema recorrente nos debates sobre a formação dos professores no Brasil.

A valorização da educação escolar, dos centros de formação universitários como loci de obtenção do licenciamento para o exercício das profissões é uma tendência observada na maioria das profissões reconhecidas e regulamentadas. No caso específico do Brasil, a constituição de suas universidades tem raízes históricas plantadas no ideal da profissionalização ${ }^{8}$, no sentido de outorgar, com seus diplomas, a licença profissional.

Segundo Giddens (1991), a confiança depositada pelos indivíduos nos sistemas peritos é responsável pela natureza das instituições modernas, "o caráter contratual, orientado para o futuro da modernidade é amplamente estruturado pela confiança conferida aos sistemas abstratos - que pela própria natureza é filtrada pela confiabilidade da perícia estabelecida" (GIDDENS, 1991, p. 87). Para o autor, isso envolve a fidedignidade atribuída pelos leigos aos sistemas 
peritos. É a confiança no conhecimento e habilidades às quais o indivíduo leigo não tem acesso efetivo. Assim; "a confiança em sistemas assume a forma de compromissos sem rosto, nos quais é mantida a fé no funcionamento do conhecimento em relação ao qual a pessoa leiga é amplamente ignorante" (GIDDENS, 1991, p. 91, grifos do autor). O autor chama a atenção para o fato de que a ciência procura manter uma imagem de conhecimento fidedigno, que se expressa numa atitude de respeito para com a maioria das formas de especialidade técnica e, ao fazê-lo, ignora toda improvisação que se sabe presente no desempenho de qualquer ofício.

\section{Antecedentes históricos do caso brasileiro ${ }^{9}$}

A discussão sobre a identidade docente foi pautada no Brasil nos anos 1980 , tanto do ponto de vista político quanto acadêmico. No final da década de 1970 e início dos anos 1980, o movimento sindical ganhou proeminência na cena política brasileira (SADER, 1981), constituindo-se em importante sujeito político que contribuiu para o desgaste do regime militar e a abertura política. Dentre as categorias que se mobilizaram neste período, o magistério figurou como um importante sujeito. A discussão sobre a identidade e o profissionalismo do magistério emergiu no debate em torno da organização dos sindicatos ${ }^{10}$. Constituído na sua imensa maioria por professores de escolas públicas, o magistério estava impossibilitado de se organizar em sindicatos, já que os funcionários públicos eram impedidos de fazê-lo.

A insistência na contituição de uma identidade de trabalhadores em educação por parte dos sindicatos docentes tinha como referência não o estatuto profissional, de acordo com o que se define como uma profissão, mas com a orientação classista trazida pelo "novo sindicalismo" pressupondo a organização horizontal dos trabalhadores por ramos e categorias econômicas. A busca de construção de uma identidade única que congregasse todos os trabalhadores

9 Alguns argumentos utilizados nesse item foram tratados em artigo anterior (ver: OLIVEIRA,2006).

10 Esse período foi marcado por luta intensa pelo reconhecimento do direito de organização sindical no contexto do novo sindicalismo brasileiro, bastante influenciado pelo princípio de organização classista que resultou criação da Central Única dos Trabalhadores (CUT). A Constituição Federal de 1988 autorizou a organização sindical de servidores públicos, que até então era vedada. 
da educação - de professores, especialistas aos funcionários administrativos e de apoio - orientou as lutas sindicais das duas décadas seguintes, refletindo no nome e estatutos das instituições sindicais criadas nessa época. Tal defesa por parte dos sindicatos persiste até hoje, tendo como sua mais recente expressão a aprovação da Lei no 12.014 de 06 de agosto de 2009, que altera o art. 61 da Lei no 9.394, de 20 de dezembro de 1996, com a finalidade de discriminar as categorias de trabalhadores que se devem considerar profissionais da educação. A nova redação dada ao artigo 61 da LDB 9394/96 atribui caráter bastante amplo ao que se define como profissionais da educação escolar básica, como se pode observar na sua nova redação:

Art.61 : Consideram-se profissionais da educação escolar básica os que, nela estando em efetivo exercício e tendo sido formados em cursos reconhecidos, são:

I - professores habilitados em nível médio ou superior para a docência na educação infantil e nos ensinos fundamental e médio;

II - trabalhadores em educação portadores de diploma de pedagogia, com habilitação em administração, planejamento, supervisão, inspeção e orientação educacional, bem como com títulos de mestrado ou doutorado nas mesmas áreas;

III - trabalhadores em educação, portadores de diploma de curso técnico ou superior em área pedagógica ou afim.

Apesar da amplitude observada na definição do que a lei 12.014 estabelece como profissionas da educação, observa-se que, na prática, permanece uma nítida separação entre professores e funcionários dentro das escolas, sendo que os processos de terceirização dos serviços de apoio escolar, tais como: vigilância, limpeza e, em alguns casos, até mesmo funções administrativas, têm reforçado ainda mais tal distinção.

A separação entre professores e especialistas e os demais trabalhadores da escola pode ser atribuída ao fato dos primeiros possuírem maior titulação e perceberem melhor remuneração. Além disso, são os especialistas e os professores, em geral, os responsáveis pela atividade-fim da escola, o que nos leva a indagar se de fato é possível pensar em uma identidade docente que inclua os que não estão diretamente envolvidos com os processos de ensino e aprendizagem. 
Outra divisão importante dentro da escola que reflete alguns obstáculos em relação a uma identidade docente é a que se observa entre professores e especialistas. Nesse caso, a divisão se revela de outra maneira. Os especialistas, que sempre ocuparam lugar de destaque na hierarquia escolar como superiores ao corpo de professores, foram alvo de fortes críticas e tiveram seu papel contestado nas lutas sindicais. Essas críticas acabaram por desautorizar, em grande medida, os especialistas em relação ao seu status e domínio profissionais. Durante os anos 1980, as críticas à Administração Escolar de orientação empresarial engendraram um novo paradigma de gestão escolar no Brasil que teve como resultado maior autonomia e participação democrática (OLIVEIRA, 2004a). As críticas à hierarquização, centralização da administração escolar e ao modelo burocrático e centrado nas especializações levou à consolidação de outras referências de gestão educacional, inscrita na Constituição Federal de 1988, Art. 206, Inciso VI. O princípio constitucional da gestão democrática do ensino público acabou por ser regulamentado em muitas redes pela escolha direta do diretor escolar pela comunidade, o que contribuiu para que a função do administrador escolar fosse se extinguindo em muitas redes de ensino. Além dos diretores, os coordenadores escolares surgem nesse contexto ocupando, em algumas redes, o papel que outrora ocupavam os especialistas nas escolas. Assim, algumas redes passaram a eleger ou contratar coordenadores pedagógicos em substituição às funções de supervisão e orientação escolares. Tais mudanças repercutiram na formação do Pedagogo.

As diretrizes curriculares para os cursos de pedagogia aprovadas em maio de 2006 centram a formação do pedagogo na docência, além de atribuir grande ênfase à gestão. Os cursos de graduação em Pedagogia no Brasil foram se constituindo no principal locus da formação docente para atuar na educação básica, na Educação Infantil e nos Anos Iniciais do Ensino Fundamental. Durante os anos 1990 houve intenso movimento de discussão e elaboração das Diretrizes para os cursos de Pedagogia envolvendo algumas entidades da área, tais como: a Associação Nacional de Pós-Graduação e Pesquisa em Educação (ANPed), a Associação Nacional pela Formação de Profissionais da Educação (ANFOPE), o Fórum Nacional de Diretores de Faculdades de Educação (FORUMDIR), a Associação Nacional de Política e Administração da Educação (ANPAE), O Centro de Estudos Educação e Sociedade (CEDES) e a Executiva Nacional dos Estudantes de Pedagogia. O resultado desse processo foi a elaboração do Documento das Diretrizes e seu encaminhamento ao Conselho Nacional de Educação, em 1999. Esse movimento se posicionava contrário à tentativa por parte do governo, à época, de consolidar a formação dos docentes de Educação Básica (para os anos iniciais) por meio do Curso Normal Superior. 
Feldfeber e Imen (2003), com base na realidade argentina, observam que as propostas de mudança para a formação docente centradas na ideia da profissionalização se inscrevem entre os novos mecanismos de regulação social estabelecidos pelo Estado que, ao mesmo tempo em que os interpelam como profissionais, estabelecem mecanismos que limitam a possibilidade de exercício autônomo da profissão submetendo-os à lógica tecnocrática e à instrumentalização do único modelo de reforma.

No caso brasileiro, as diretrizes buscaram regulamentar a formação do pedagogo adequando-a à tendência crescente de os professores passarem a ocupar, por meio de escolha livre e direta de seus pares e da comunidade, as funções antes designadas aos especialistas e a capacitarem-se para uma organização mais flexível do trabalho escolar, exigente de elaboração coletiva. Mas as críticas que tais Diretrizes recebem no sentido de transformarem o pedagogo em professor expressam uma das faces corporativas da escola e isso demonstra que, ao contrário do que propugnavam os sindicatos nos finais dos anos 1970 e início dos 1980, e do que determina, na atualidade, a Lei 12.014, a construção de uma identidade profissional que implique na aceitação da condição de serem todos docentes e de poderem se organizar de forma horizontal nas escolas encontra vivas resistências por parte de setores do magistério.

\section{A profissão docente ante uma nova regulação: considerações finais}

As reformas educacionais dos anos 1990 foram implementadas em um período de relativa estabilização da luta político-sindical, marcada por fraca mobilização de base e burocratização das direções sindicais. Observa-se relativo distanciamento entre o sindicato e o cotidiano escolar, no sentido de que há dificuldades em acompanhar as mudanças mais recentes que atingem a escola, assim como repercussões dessas sobre a subjetividade dos professores (TENTI FANFANI, 2005; OLIVEIRA; MELO, 2004). Ao mesmo tempo, essas reformas trazem consigo uma forte retórica que valoriza aspectos da luta por uma educação mais democrática. As noções de coletividade, autonomia e participação são fortemente evocadas nos documentos das reformas educativas atuais (UNESCO/ CEPAL, 2005), porém compreendidas dentro de uma abordagem que privilegia o elemento da flexibilidade. É possível observar que essa maior flexibilidade, tanto nas estruturas curriculares quanto nos processos de avaliação, corrobora com a ideia de que estamos diante de novos padrões de organização também do trabalho escolar que podem estar forjando um novo perfil de trabalhadores 
docentes e uma nova identidade, o que incide sobre o movimento de profissionalização do magistério.

Não há como negar que as mudanças que o mundo passou a viver nas últimas décadas do século XX apontam para novas formas de organização da produção, do trabalho, da vida econômica e, é claro, a escola não está imune a tais processos. Observa-se uma regulação social que não está mais fundada no trabalho regulamentado, na sociedade do pleno emprego, no Estado provedor. A reestruturação produtiva traz um novo modelo de acumulação denominado flexível e enseja com ele novas formas de organização do trabalho, menos fragmentadas, menos rígidas, sob orientação mais flexível, exigindo maior plurifuncionalidade e polivalência (CORIAT, 1994). As profissões, em geral, tendem a perder força nesse contexto incidindo sobre a identidade dos que trabalham (BAUMAN, 2005). Os trabalhadores passam a buscar novas formas de ocupação e, consequentemente, de formação, para adaptarem-se às novas exigências. Esse caráter flexível das ocupações chega à escola de duas formas: no objeto dos docentes - eles terão que adequar seu trabalho às exigências atuais, já que formam a força de trabalho para esse mundo em mudança; e na organização do seu próprio trabalho - que também tende a adotar cada vez mais o caráter de maior flexibilidade e autonomia que o trabalho em geral assume.

Os professores se encontram assim diante de uma nova ambivalência. Se por um lado as formas mais flexíveis e autônomas de organização do trabalho lhes trazem ganhos de autonomia e maior controle sobre suas atividades, por outro lado essa mesma organização lhes retira poder e controle como um grupo profissional, à medida que os demais sujeitos que participam da escola e do sistema se encontram agora investidos do poder de cobrar e exigir prestação de contas do que é realizado no espaço escolar.

Se como afirma Nóvoa, a identidade é um espaço de permanente conflito, será no espaço dessa ambiguidade vivida no cotidiano escolar que certamente novas identidades poderão ser forjadas e novos sentidos poderão ser atribuídos ao movimento de profissionalização docente.

\section{REFERÊNCIAS}

ASSUNÇÃO, A.A.; OLIVEIRA, D.A. Intensificação do trabalho e saúde dos professores. Revista Educação \& Sociedade, Campinas: CEDES/UNICAMP, v. 30, n. 107, maio/ago. 2009. 
APPLE, M. W.. Trabalho docente e textos: economia política das relações de classe e de gênero em educação. Porto Alegre: Artes Médicas, 1995.

ARROYO, M. Mestre, educador e trabalhador: organização do trabalho e profissionalização. Tese (Concurso de Professor Titular) - FAE/UFMG, Belo Horizonte, 1985.

BAUMAN, Z. Identidade. Rio de Janeiro: Zahar Editores, 2005.

BITTAR, M.; FERREIRA JÚNIOR, A. Proletarização e sindicalismo de professores na ditadura militar (1964-1985). 1. ed. São Paulo: Pulsar, 2006.

BRASIL. Constituição da República Federativa do Brasil. 18. ed., atualizada e ampliada. São Paulo: Saraiva, 1998.

BRASIL. Lei de Diretrizes e Bases da Educação Nacional. Lei n. 9.394 de 20 dez.1996.

BRAVERMAN, H. Trabalho e capital monopolista: a degradação do trabalho no século XX. Rio de Janeiro: Guanabara, 1985.

CARNOY, M.; LEVIN, H. Escola e trabalho no Estado capitalista. São Paulo: Cortez, 1993.

CONTRERAS, J. Autonomia de professores. São Paulo: Cortez, 2002.

CORIAT, B. Pensar pelo avesso: o modelo japonês de trabalho e organização. Rio de Janeiro: Revan/UFRJ, 1994.

COSTA, M. C. V. Trabalho docente e profissionalismo. Porto Alegre: Sulina, 1995.

DURKHEIM, E. Lições de sociologia: a moral, o direito e o Estado. São Paulo: T. A. Queiroz: Ed. da USP, 1983, 206p. (da quarta à nona lição)

DURHAM, E. O ensino superior na América Latina: tradições e tendências. Revista Novos Estudos, São Paulo, CEBRAP, n. 51, jul. 1998.

ENGUITA, M. F. A ambigüidade da docência: entre o profissionalismo e a proletarização. Revista Teoria \& Educação, n. 4, 1991.

FELDFEBER, M.; IMEN, P. A formação continuada dos docentes: os imperativos da profissionalização em contexto de reforma. In: CARAPETO, N. (Org.). Formação continuada e gestão da educação. São Paulo: Cortez, 2003.

GIDDENS, A. As conseqüencias da modernidade. São Paulo: Editora UNESP, 1991.

GIDDENS, A. Modernidade e identidade. Rio de Janeiro: J. Zahar, 2002. 
HARGREAVES, A. Os professores em tempos de mudança: o trabalho e a cultura na Idade Pós-Moderna. Editora McGraw-Hill de Portugal. Alfragide-Portugal. 1998.

HYPÓLITO, A. L. M. Trabalho docente, classe social e relações de gênero. Campinas: Papirus, 1997.

LESSARD, C. ; TARDIF, M. Les transformations actuelles de l'enseignement: trois scénarios possibles dans l'évolution de la profession enseignante? In: LESSARD, C. ; TARDIF, M. La profession d'enseignant aujourd'hui: évolutions, perspectives et enjeux internationaux. Montréal (Canadá): La Presses de L'Université Laval, 2004.

NORONHA, M. M. B. Condições do exercício profissional da professora e os seus possiveis efeitos sobre a saúde: estudo de casos das professoras do ensino fundamental em uma escola pública de Montes Claros, Minas Gerais. Dissertação (Mestrado) Programa de Pós-graduação em Saúde Pública, Mestrado Interinstitucional UFMG / UNIMONTES Belo Horizonte, Montes Claros, 2001. ).

NÓVOA, A. Os professores e o "novo" espaço público da educação. In: TARDIF, M.; LESSARD, C. Oficio de professor: história, perspectivas e desafios internacionais. Petrópolis: Vozes, 2008.

NÓVOA, A. Os professores e a história da sua vida. In: NÓVOA, A. (Org.). Vida de professores. 2. ed. Porto: Porto Editora, 2000.

NÓVOA, A. (Org.). Os professores e a sua formação. Lisboa: Publicações D. Quixote, 1993.

NÓVOA, A. (Org.). Profissão professor. Porto: Porto Editora, 1991.

OLIVEIRA, D. A. A reestruturação do trabalho docente: precarização e flexibilização. Educ. Soc., v. 25, n.89, p.1127-1144, dez. 2004a.

OLIVEIRA, D. A. A reestruturação do trabalho docente: precarização e flexibilização. Educ. Soc., v. 25, n.89, dez. 2004 b.

OLIVEIRA, D. A. Os trabalhadores docentes no contexto de nova regulação das políticas educacionais na América Latina. Belo Horizonte: Faculdade de Educação / UFMG, 2006. (Relatório de Pesquisa Capes).

OLIVEIRA, D. A.; MELO, S. D. Estudio de los conflitos en los sistemas educativos de la región: agendas, actores, evolucion, manejo e desenlaces. Santiago: LPP / UERJ / OREALC / UNESCO, 2004. (Relatório de estudo de caso do Brasil).

POPKEWITZ, T. S. Reforma Educacional: uma política sociológica. Porto Alegre: Artes Médicas, 1997. 
RODRIGUES, M. L. Sociologia das profissões. Oeiras (Portugal): Celta Editora, 2002.

SADER, E. Quando novos personagens entraram em cena: Experiências e lutas dos trabalhadores da grande São Paulo 1970 - 1980. Rio de Janeiro: Paz e Terra, 1981.

SHIROMA, E. O. O eufemismo da profissionalização. In: MORAES, M. C. M. (Org.). Iluminismo às avessas: produção de conhecimento e políticas de formação docente. Rio de Janeiro: DP\&A, 2003.

TENTI FANFANI, E. Consideraciones sociologicas sobre profesionalización docente. Educ. Soc., Campinas, v. 28, n. 99, maio/ago. 2007.

TENTI FANFANI, E. La condición docente. Buenos Aires: Siglo Veintiuno Editores, 2005.

TORRES, M. G.; MOUTA, C.; MENESES, A. L. Investigação, profissão, profissionalidade e profissionalização dos educadores de infância. Cadernos de Educação de Infância, jan./mar. 2002.

UNESCO-CEPAL. Invertir mejor para invertir más: financiamiento y gestión de la educación en América Latina y el Caribe. Santiago: OREALC/UNESCO-CEPAL, 2005.

VIEIRA, S. R. Diretrizes curriculares para o curso de pedagogia: pedagogo, docente ou professor? 2008. Disponível em: <http://www.tede.ufsc.br/tedesimplificado// tde_busca/ arquivo.php?codArquivo=148>.

WEBER, M. Economia e sociedade: fundamentos da sociologia compreensiva. Brasília: Editora Universidade de Brasília, 1991.

Texto recebido em março de 2010 .

Texto aprovado em junho de 2010 . 